\title{
Fotobiografia: por uma metodologia da estética em antropologia
}

Photobiography: for a methodology of the aesthetic in antropology

\author{
FABIANA BRUNO
}

Jornalista, doutora em Multimeios, professora da Faculdade Panamericana de Arte e Design e pesquisadora do Grupo de Reflexão

Imagem e Pensamento (GRIP) vinculado ao CNPq

E-mail: fabybruno@uol.com.br

\section{RESUMO}

As Fotobiografias de pessoas idosas apresentadas neste estudo nasceram de uma proposta metodológica a qual, sem desprezar o verbal, priorizou e deu confiança ao trabalho das imagens. Por serem carregadas de memórias, elas, as imagens puderam, diferentemente do verbal, "refletir" e "pensar", "redescobrir" e "esquecer" a memória de pessoas idosas. A pesquisa desenvolveu etapas de um percurso metodológico de natureza visual trabalhando com conjuntos fotográficos compostos por 20, 10 e três fotografias. Cinco Fotobiografias acompanham o estudo e nelas, o verbal e o visual guardam em si, relevância singular, isto é, partilham diferentemente uma mesma tarefa: representar a vida de uma pessoa idosa como um pequeno filme, que ela monta, desmonta ou remonta.

Palavras-chave: Fotobiografia; Fotografia; Memória; Velhice; Antropologia visual

\section{Abstract}

The Photobiographies of elderly presented in this study from a methodological approch which priorized and gave emphasis to the work of images, though not despizing the oral expression. The images, being by themselves, full of memories could, differently from the oral expression, "reflect", "think", "rediscover", "forget" the memory of old people. Based on the visual expression, this research was developped in different stages working with sets of 20, 10 and three photos. Five Photobiographies are attached to the study and the oral and the visual expressions contained in them have their own characteristic that is, share in different ways the same task: they represent an old person's life as a short film that he/she can assemble, disassemble or reassemble.

Keywords: Photobiography, Photography, Memory, Old age, Visual anthropology 
s Fotobiografias de cinco pessoas idosas apresentadas neste estudo nasceram de uma proposta metodológica a qual, sem desprezar o verbal, priorizou e deu confiança ao trabalho das imagens. As fotografias puderam diferentemente do verbal, "refletir", "pensar" e "redescobrir" a memória e representar a trajetória de um idoso como um pequeno filme, que ele monta, desmonta e remonta, a partir de etapas metodológicas que partiram de arranjos visuais compostos por 20, 10 e três fotografias.

Esta proposta metodológica se definiu como um estudo verbo-visual "das imagens" - numa primeira instância, a fotográfica - e "da memória" representada pelas narrativas de histórias de vida de pessoas idosas. A conjugação verbo-visual se deu pela intersecção entre as operações de escolha, montagem e remontagem de fotografias guardadas por eles ao longo da vida e pelos relatos orais elaborados espontaneamente durante o percurso da pesquisa.

O estudo foi se organizando numa vertente de cunho antropológico, comunicacional, visual e estético em busca das "representações imagéticas" escolhidas pelos participantes da pesquisa - homens e mulheres octogenários - como formas de "evocar" e de "sintetizar", ora sua própria "história de vida', ora o complexo 'ritual de passagem' que vivenciaram. A pesquisa procurou examinar como essas pessoas organizam, isto é, como "formam" (a imagem enquanto "forma") e "montam" (a problemática da "montagem") as fotografias por elas selecionadas, com vistas à evocação e à transmissão de sua própria existência.

A proposta, deste modo, caminhou numa tentativa de exploração do "trabalho da memória" na velhice, vasculhando baús fotográficos, num estudo de reconhecimento do que guarda e conserva, o que forma e ordena, o que configura e - talvez - transfigura em termos de uma constituição de história de vida. $\mathrm{O}$ processo de pesquisa fez germinar e permitiu a eclosão de uma tríplice ordem de reflexões: "Montagens Foto-Biográficas", "Formas FotobioGráficas ("Formas que Pensam") e "Imagem-Escrita nas Fotobiografias". Essas temáticas complexas foram encaradas não somente para tornar nossos propósitos viáveis no âmbito deste estudo, mas para não perder o horizonte que fixamos nessa pesquisa: a construção possível de cinco "Fotobiografias", 
capazes de expressar de maneira estética singular "histórias de vida" em termos verbos-visuais e em perspectivas tanto antropológicas como estéticas, conjugando as singularidades e as complementaridades entre imagens, palavras e textos, fazendo-as interagir com as três reflexões temáticas referidas:

a) $\mathrm{O}$ que significa a questão da montagem em nosso trabalho de elaboração verbo-visual de "história de vida"?

b) A ideia que as imagens (todas as imagens) são "formas que pensam" quando, entre elas, se associam;

c) Como repensar concretamente as questões de complementaridades entre visual e verbal - na constituição de uma nova maneira de pensar as histórias de vida - a partir deste trabalho de campo?

Perseguindo um modo de pensar que priorizava o trabalho das imagens para a elaboração de cinco Fotobiografias, cada uma delas, apresentadas num volume independente, este trabalho procurou conservar a originalidade do estudo no tocante ao trabalho visual, criado para as apresentações das histórias de vida, a partir das fotografias, especialmente no que diz respeito à criação e reflexão "formal” gráfica - das formas e da montagem.

As Fotobiografias procuraram mostrar, com particularidade, como as pessoas idosas constroem suas histórias, por meio de suas memórias, e a partir de um detalhe em um registro fotográfico, revelando um tipo de registro de memória pessoal e familiar, que se concretiza sobre a forma de imagem e evoca as próprias imagens. Tendo esta pesquisa aberto diversos pontos de luz ao longo do percurso - caminho este construído pela confiança dada à imagem no trabalho conjunto com a palavra - aportar para uma única vertente poderia ser redutor. A própria opção pelo fazer metodológico nos assegurava desta condição, de multiplicidade de olhar, de interesses, de interrogativas e convites a novas questões.

Reserva-se ao leitor, que a partir de agora se volta a acompanhar o que foi este caminhar, a observação de que este estudo foi pensado como "uma forma" para ser desdobrado e desvendado. O corpus da pesquisa apresenta cinco volumes finais, contendo as Fotobiografias da rede de informantes como proposta de um continuum a conjugar montagem, desmontagem e remontagem das histórias de vida de pessoas idosas, assim como se fosse um pequeno filme. 


\section{A IDEIA DE FotobiogRAFIA}

A Fotobiografia, a que se pretendeu, pensa a imagem - predominantemente fotográfica neste caso - não como um mero objeto, mas como um "acontecimento" - ora epifania, ora fenômeno no sentido etimológico das palavras -, um campo de forças que se cruzam e um sistema de relações que coloca em jogo diferentes instâncias enunciativas (o verbal), figurativas e perceptivas (o visual). Uma Fotobiografia é, para esta pesquisa, esse esforço intenso de ordem arqueológica, essa tentativa de descobrir e, na medida do possível, desvendar, camada após camada, imagem após imagem - dentro, embaixo, em cima, nos arredores, nos entrecruzamentos de figuras de ordens múltiplas - traços e vestígios de emoções, sensibilidades, sentimentos, sempre, fragmentos da vida de uma pessoa ímpar. Para Didi-Huberman:

tentar uma arqueologia é sempre tomar o risco de pôr, uns aos lados dos outros, pedaços de coisas que sobreviveram, coisas necessariamente heterogêneas e anacrônicas, já que provenientes de lugares separados e de tempos disjuntos por lacunas. Ora, esse risco tem como nome - dirá ele - imaginação e montagem [ grifos dele] (2006: 26-27).

1 - Doutrinas filosóficas que procuram explicar os seres pela finalidade aparente a que parecem destinados.
O autor acrescentará: "A montagem será precisamente uma das respostas fundamentais a esse problema de construção da historicidade”. (Idem: 26-27) E acrescentaríamos, uma resposta também aos problemas das culturas, das sociedades, das pessoas... "A medida em que a montagem não está simplesmente orientada, ela escapa às teleologias [1] e torna visíveis as sobrevivências, os anacronismos, os encontros de temporalidades contraditórias que afetam cada objeto, cada acontecimento, cada pessoa, cada gesto. Assim sendo, o historiador renuncia a contar 'uma história' mas, ao mesmo tempo, consegue mostrar que a história não se faz sem todas as complexidades do tempo, todas as camadas da arqueologia, todos os ponteados, os interstícios do destino" (Ibidem: 27).

As Fotobiografias dos cinco informantes que foram desvendadas ao longo do trabalho não escaparam a esse processo, cuja singularidade repousou precisamente na constatação de que a "construção da historicidade" de cada uma dessas vidas se dará principalmente a partir de imagens que elegeram e 
montaram. Não foram denegadas deste processo de montagem as palavras. Sabemos, como as palavras - ao se concatenarem - conseguem, também, se constituir em frases, em períodos, conseguem formar capítulos e desembocar na construção, por exemplo, de discursos, romances, biografias, livros de memórias. O que, então, será essencial observar é a maneira como se dará a montagem - ora através de imagens, ora de palavras ou de ambas - e o modo cognitivo e a dimensão estética de cada um desses suportes oferecidos em "termos" e "figuras" de eclosão, construção e configuração dessas "histórias de vida". Algumas das funcionalidades singulares da "montagem", quando relacionadas a fotografias e na elaboração de Fotobiografias, foram realçadas por razões peculiares que surgiram no decorrer dessa pesquisa. No percurso do trabalho de campo não foi adotado o imperativo para que os informantes ordenassem os seus conjuntos fotográficos (da ordem de 20 para começar, de dez, em seguida, e depois três), aos quais nos remetiam, em momentos temporalmente distantes. A realidade foi de outra ordem. Foram eles que despertaram para a importância dos arranjos ("montagens") que constituíam, por vezes, com hesitações, resistências e outras saudades.

Descobrimos, desta vez, que uma prancha, outrora composta por 28 fotografias por dona Celeste [2] foi, de repente, segmentada, recortada, desfragmentada. Das 28 fotografias escolhidas originariamente, 11 delas permaneceram expostas - aliás, quase "perdidas" - no meio de 17 "janelas", que se abriram de repente: janelas, telas, brancuras, quadros, transparências opacas, buracos, perdas, desaparições? Ou, ainda, fantasmas que foram e voltaram a habitar as sinapses da memória e do imaginário das pessoas, confabulando $o$ quê e como seriam e se dariam suas próximas reminiscências e reaparições? Suas "sobrevivências". Suas "supervivências". [FIG. 1]

Esta "remontagem" é da ordem de um verdadeiro estouro, uma espécie de arrombamento da primeira montagem, uma espécie de dissolução e de desaparecimento de uma primeira Fotobiografia e, ao mesmo tempo, a necessidade de se reconstruir outra. Esse terremoto obrigou a uma reordenação das 11 fotografias restantes. Onze fotografias não apenas privadas agora das relações que mantinham até lá com as demais, mas também 11 fotografias que conduzem a uma nova e necessária "montagem”, uma "outra Fotobiografia”. [FIG. 2]
2 - Cinco informantes integraram a pesquisa iniciada em âmbito de Mestrado pelo Programa de PósGraduação em Multimeios (Instituto de Artes-Unicamp). O trabalho foi ampliado e finalizado em doutorado (2009), pelo mesmo programa com apoio da Fapesp. 
Figura 1

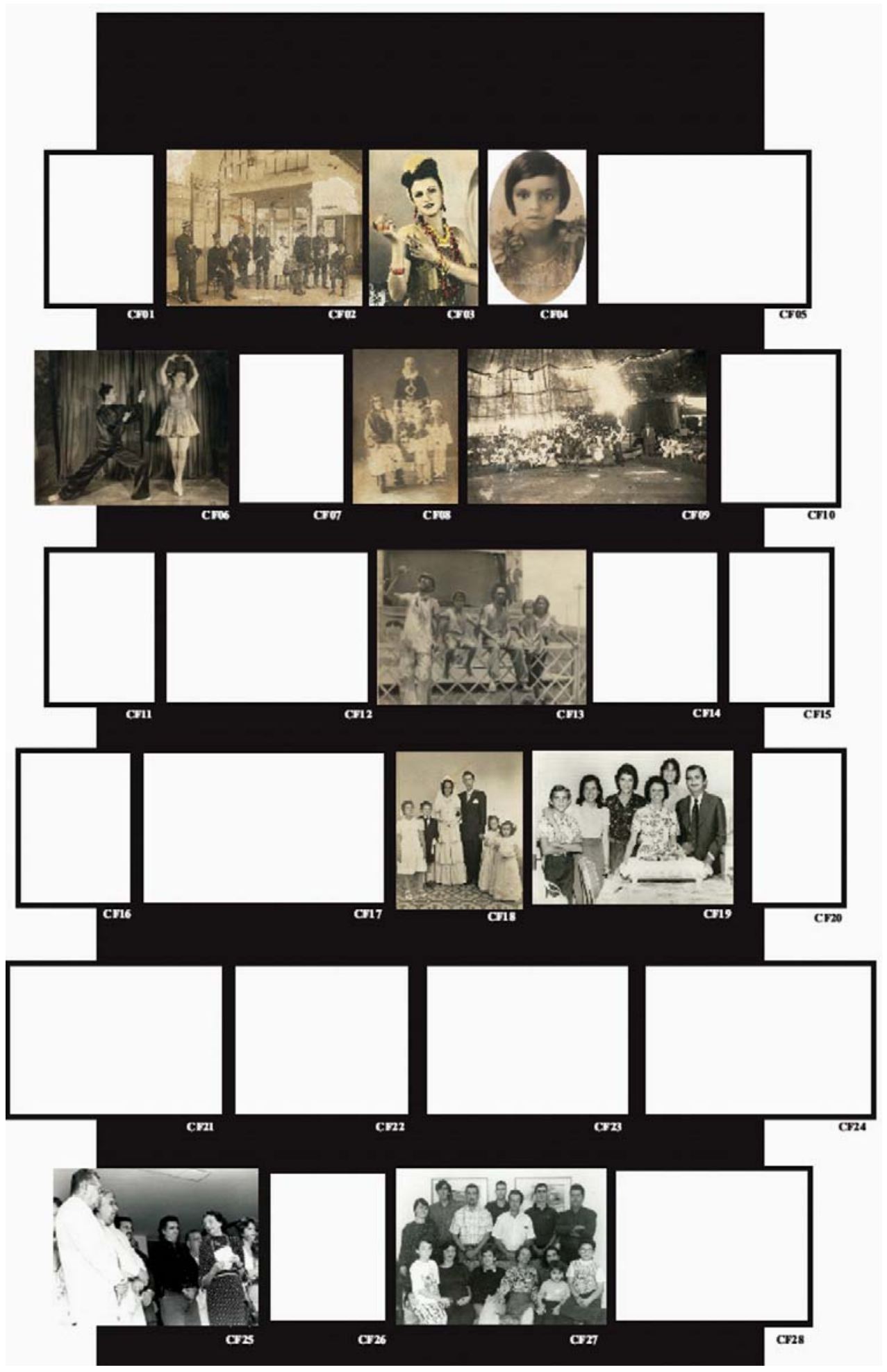


Artigos \& Ensaios

\section{Figura 2}

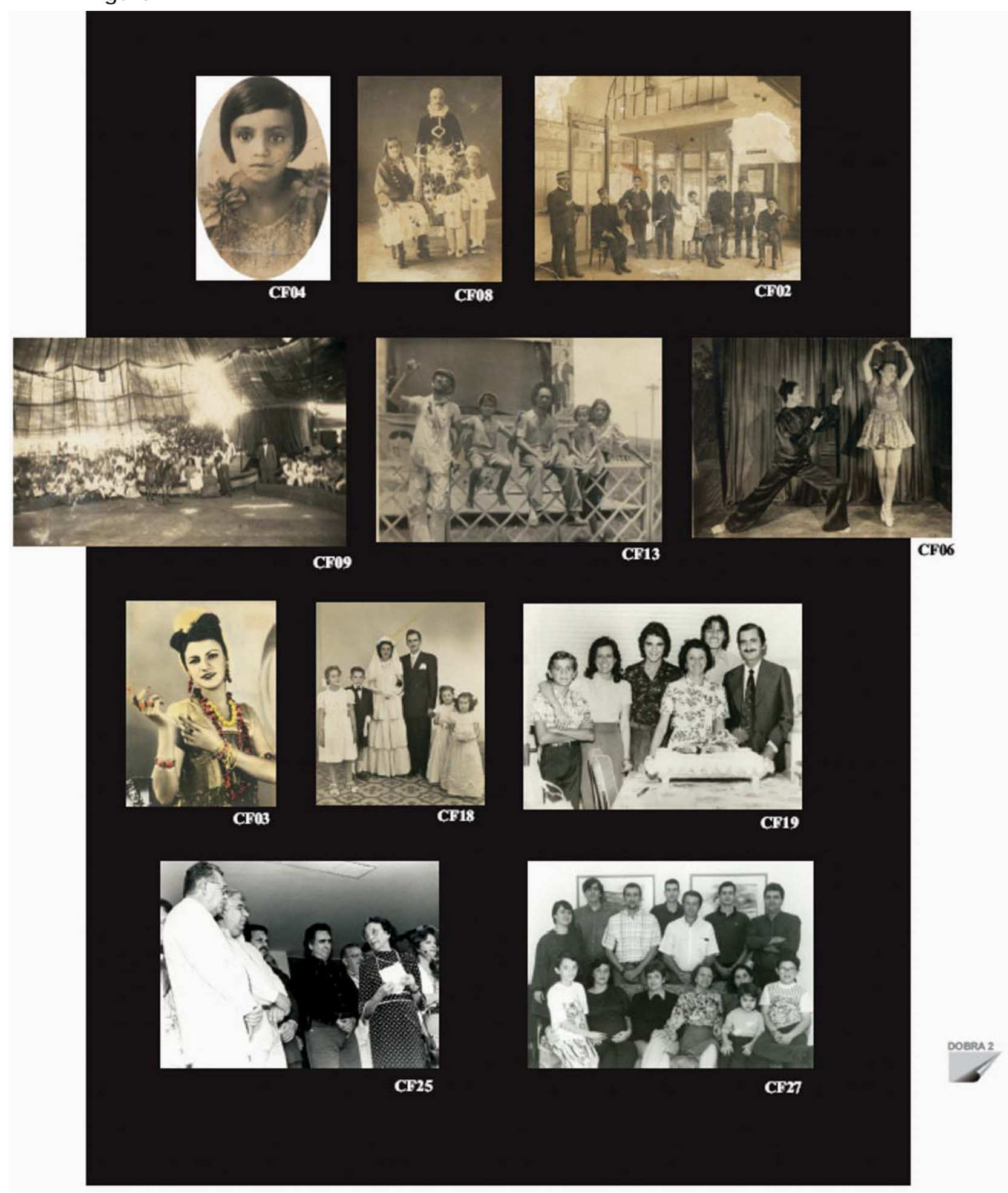

RESGATE - Vol. XVIII, No. 19 - jan./jul. 2010 - BRUNO, Fabiana - p.27-45 
É assim - recorrendo mais uma vez às escolhas de dona Celeste que descobriremos que o pequeno rosto com olhos grandes, marcas de sua primeira entrada na vida do circo (foto CF04) no primeiro arranjo de 28 fotografias, passará, no segundo arranjo, a ser a primeira do novo lote. Da mesma maneira, notar-se-á que, quando dona Celeste elabora esse outro conjunto, ela desloca a foto CF03 - vestida de Carmem Miranda, apoteose de sua existência no circo - e dispõe a mesma ao lado da fotografia de celebração de seu casamento, com o farmacêutico Walter Ferrari: (foto CF18). Essa segunda montagem realça, nas sete primeiras fotografias encadeadas por dona Celeste, algo que as quatro últimas reconfiguram num outro patamar existencial. Falam, de um lado, da "grande família do circo"; de outro, da "grande família humana" que Dona Celeste construiu, sendo mulher e vivendo em outra época cultural.

Descobriu-se ainda que, no caso de dona Celeste (observação válida, aliás, para os outros informantes), devemos ir, mais adiante, no tocante à(s) significação(ões) possível(eis) dessas reformulação e reorganização de suas fotografias, da primeira à segunda montagem. Em qual sentido? No sentido de que dona Celeste não apenas teve de condensar e conglomerar marcos importantes de sua existência, mas teve também de renunciar e eliminar outros momentos que faziam parte da prancha inicial de suas 28 fotografias.

O conjunto das fotografias assim "abandonadas", no caso dela, fala eis o teor da nossa nova pergunta - de quais lugares, de que épocas da sua vida, de quais figuras continuam vivendo na sua memória? Há de se ir mais longe. Será que as 17 fotografias retiradas - na ordem - não se constituiriam num roteiro possível de sua vida, num outro florilégio importante de sua vida, numa outra parcial Fotobiografia. Eis o que não podemos definir a priori, mas que, no entanto, a(s) montagem(ns) nos revela(m) com clareza. [FIG. 3]

$\mathrm{Na}$ realidade, os cinco informantes ao passarem de uma primeira montagem para uma segunda fizeram emergir, cada um ao seu modo, uma terceira mensagem, composta de outras facetas particulares de sua Fotobiografia. Essas fotografias "excluídas e abandonadas" representam uma terceira montagem e uma não menos importante "história de vida". O que Roland Barthes (1970) teria designado de "terceiro sentido" e que 
Figura 3

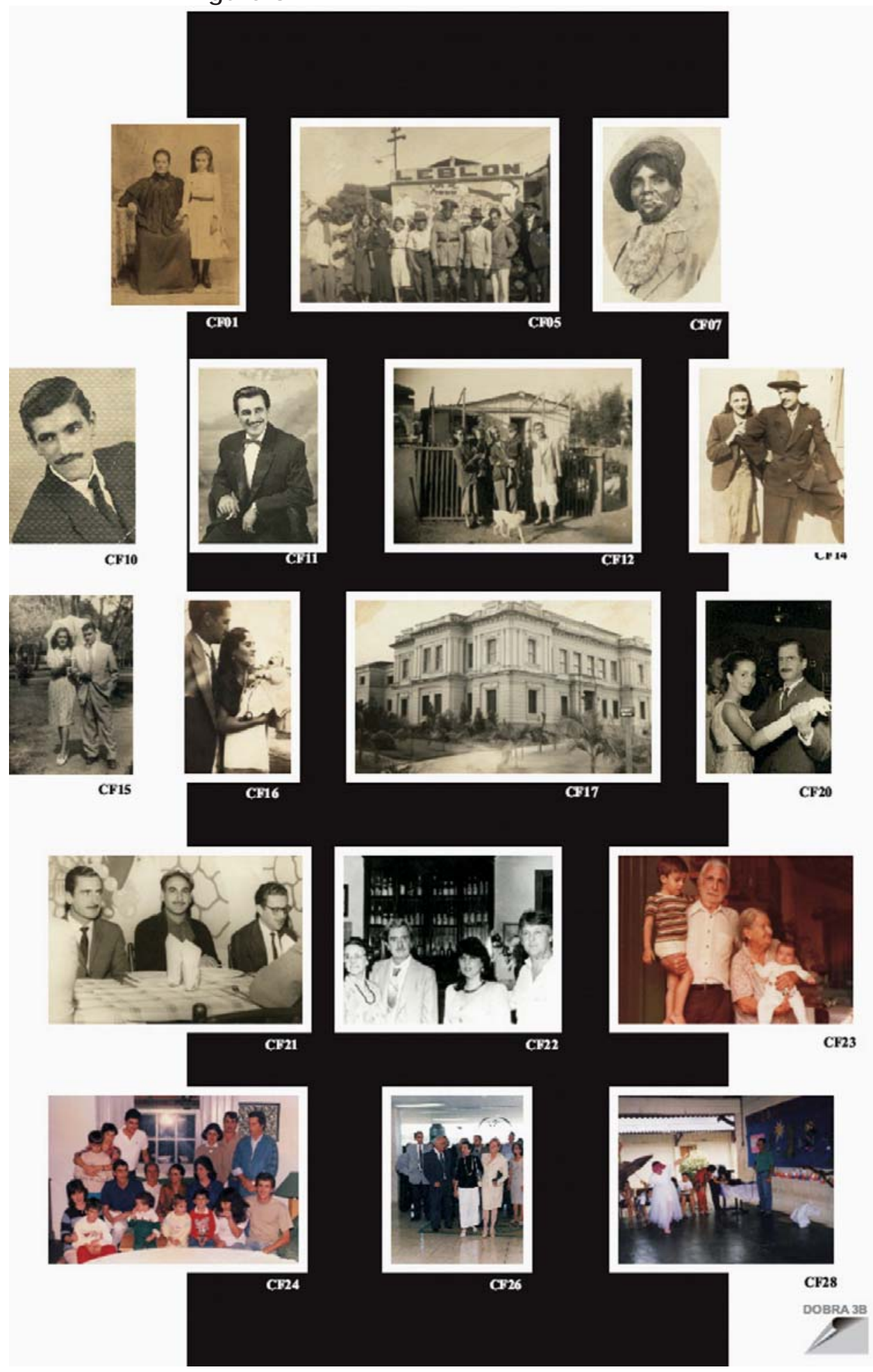

RESGATE - Vol. XVIII, No. 19 - jan./jul. 2010 - BRUNO, Fabiana - p.27-45 
3 - Fazemos aqui alusão a DidiHubermann (2006: p.11-52) e seu belíssimo trabalho "L'image brûle" sobre as imagens e as falenas.
Albert Piette (1992) chamaria de "modo menor da realidade". No caso desta pesquisa, pretendia-se apenas chamar a atenção do leitor para os desdobramentos heurísticos que as imagens nos proporcionam de uma maneira inequívoca.

\section{Memória de Memórias}

Quando produzimos fotos ou as deixamos aos cuidados de outros, é, na maioria dos casos, para guardar a lembrança de acontecimentos, de encontros ou de momentos rituais de todo tipo, que acompanham nossas vivas. Esses eventos foram, ora, meticulosamente organizados, estandardizados em termos de seus preparativos (casamento, festa de formatura); ora quase fortuitos. Muitas vezes, queríamos simplesmente - na hora de fazê-la - privilegiar um instante, uma impressão, uma surpresa ou um encantamento. Lembranças, memórias que geralmente não passam de divertimentos, momentos lúdicos, ocasionais, banais, muitas vezes, tendo como destino: o esquecimento.

Muitas fotografias, de fato, morrerão, segundos após o seu nascimento, graças a nossas máquinas guilhotinas, mas tantas outras sobrevirão. Será que "morrer", aliás, representa o verbo apropriado quando se trata de fotografias que compõem as nossas histórias de vida? É verdade que podem deixar de existir ou que podem vir a apagar-se. Pois, o que dizer então desses pequenos montões de cinzas que um sopro de vento é capaz de fazer também re-arder? [3] Nossa memória está, sim, em evolução e reorganização constantes.

O que esses interlocutores reuniram são acontecimentos, simples acontecimentos. Dito isto, se existir, todavia, algo novo nessas fotografias reencontradas, escolhidas, ordenadas dois componentes são referências da memória humana: o tempo e o espaço. Sem temporalidade e espacialidade não existem verdadeira memória, verdadeiras lembranças que possam nascer. Deve-se acrescentar um outro dado que nos parece fundamental. Neste caso, as dimensões sociais, mas principalmente afetivas, da memória são patentes. Basta assim rever os cinco conjuntos de fotografias para se dar conta que moldadas pelo tempo e dilatadas por outros espaços de vivência humana, as imagens expressam antes de tudo dados 
afetivos, sensíveis, emocionais. Eis, sem dúvida, uma das configurações maior (pattern) das fotografias escolhidas no tempo da velhice e de que se nota potencialmente no início desta pesquisa: uma configuração e uma condensação de uma história em torno de um núcleo: a família natural, as famílias humanas (escolar, profissional, política...).

De certo não há a intenção de limitar tal configuração como única e universal. É muito provável que uma amostra mais consequente do que esta revelaria outros pólos. É mais provável ainda que os patterns, referenciais de histórias de vida mais próximas no tempo, possam revelar novos aspectos não menos significativos de reconfigurações de nosso universo atual. Para o que nos diz respeito e no quadro exíguo de nossa amostra é evidente que um desses patterns é aquele da família.

No âmbito deste trabalho de pesquisa - inicialmente de mestrado, e doutorado em seguida -, não havia necessariamente balizas críticas definidas e nenhuma ambição, senão as de não nos atrelarmos diretamente a um modelo de história de vida, nem de lançar mão ao puro acaso. O horizonte primeiro consistiu em não definir de antemão nossa geografia, mas ao contrário, em deixar a geografia humana e seus interlocutores questionarem passo a passo. Não era a intenção apenas traçar histórias de vida e sim pensá-las através de seus labirintos de signos, de figuras, de palavras, de silêncios, de contextos. Não era o propósito se fechar em sistemas sociológicos enclausurados em determinados parâmetros.

Era necessário dar confiança às imagens na construção de histórias de vida. Isto significava, portanto, entender, com a contribuição de outros autores, em que medida a fotografia representa um excelente explosivo para fazer ressurgir lembranças. Dito isso, lamentava-se o fato de que, tendo despertado essas lembranças, logo estas mesmas desapareciam do cerne das pesquisas. Eram engavetadas, ou seja, escondiam-se as próprias fontes, tornando-se apenas "detonadores virtuais". Sem minimizar o trabalho da palavra na elaboração de uma história de vida, o estudo caminhou para dar uma relevância especial ao trabalho das imagens na constituição de uma história de vida. Essas prioridades heurísticas fizeram com que os interlocutores, em momentos diferentes, tivessem que esco- 
Iher ou selecionar aproximadamente 20, 10 e três fotografias, que melhor representassem o caminho de suas singulares existências. Este trabalho de síntese, de redução, que se impunha sob pena de cair numa disseminação de significação abusiva, nos fazia descobrir, às avessas, que cada etapa representava uma montagem, uma desmontagem, uma remontagem de fotografias, que permitiam viver tais fotogramas, como na montagem de um filme. Entre as mãos, encontravam-se pequenos filmes de diferentes montes, porém, articulados e expressivos. Tínhamos entrado no mundo do cinema. Era a primeira grande felicidade de nossa aventura: poder olhar as histórias de vida como pequenos filmes.

No imenso campo das Ciências Sociais, o papel da arte mereceu até hoje uma insuficiente atenção. Permaneceu a lembrança da leitura difícil do primeiro capítulo "A Ciência do Concreto", do Pensamento Selvagem, de Claude Lévi-Strauss. O pai do Estruturalismo procurava entender, então, a especificidade do chamado "pensamento selvagem", concreto, sensível, "próximo da percepção e da imaginação", ao lado de um outro, mais abstrato, mais lógico. Independentemente dos desdobramentos existentes entre esses dois modos de pensamento, não se deu atenção suficiente a outro fato não menos importante: a arte e a atividade artística. Segundo os termos de LéviStrauss (1969), podemos aludir que a arte se insere a meio caminho entre o conhecimento lógico e o pensamento mítico, ou mágico; pois o artista, podemos considerar, é uma combinação do sábio e do bricoleur. Lévi-Strauss, que sempre foi amante da arte, sonharia ainda conosco, que a arte, mas, sobretudo, o homem e as culturas, ao se reunirem, conseguiriam, um dia, dar valor aos traços profundos, que unem percepção e imaginação e abstração e lógica.

Eis, enfim, o que nos conduziu a apresentar sobre a forma de cinco volumes fotobiográficos estas histórias de vida. Como pesquisadora, tomei partido de conceber história de vida, em termos do estético e artístico. Tal audácia fez com que estas histórias de vida pertencessem não apenas a uma realidade e sim a uma cultura humana e que a forma, essa construção, fosse habitada por um pensamento.

No processo de conceber as cinco Fotobiografias, tornou-se notável a presença de uma densa profundidade de significados que foram sendo teci- 
dos no decorrer do longo percurso da pesquisa. Afinal tratava-se de documentos verbo-visuais originados de diversos verbos: do ver, do olhar, do sentir, do escolher, do excluir. Esta pluralidade de ações, do reino do sensível, nos provocava a encontrar o fio, o que seria o elemento desencadeador do eixo de cada composição e ao mesmo tempo, tentávamos antever o resultado destas montagens, da eficácia do "roteiro" do filme, de um pequeno filme com o propósito definido, nesta pesquisa, de contar uma história de vida. Foi então que ficou muito visível que a montagem e a forma desta história já haviam sido concebidas pelos próprios informantes. Restava a tarefa de considerar a construção do que eles mesmos propuseram ao desenvolverem suas montagens; entendemos que era necessário valorizar o conjunto mais completo de 20 fotografias (resultado da primeira escolha) sim, mas também as lacunas, os intervalos, os vazios gerados pelas fotografias excluídas (resultado da segunda escolha) e, suas histórias; obviamente, igual importância deveríamos dedicar a síntese de três fotografias (resultado da terceira escolha).

Guiados por esse entendimento, interessava reunir todo o trabalho de escolha e de montagem, proporcionado pela metodologia, para encontrar neste contexto como essas fotografias montadas e remontadas, abandonadas ou reafirmadas poderiam constituir o filme de vida dos informantes.

A seguir exemplifico a estrutura desenhada que compõe as páginas das Fotobiografias.

A composição estética em camadas é uma das características fundamentais das cinco Fotobiografias, decorrentes de momentos e de resultados, de escolhas e de montagens dos conjuntos de 20 , de 10 e de três fotografias. O leitor encontrará logo nas primeiras páginas um índice que contempla esses três conjuntos fotográficos: no rodapé da página (margem inferior) o conjunto maior de cerca de 20 fotografias, respeitando a ordem designada pelo informante; à direita o segundo conjunto de aproximadamente 10 fotografias também na ordem de montagem e à esquerda as três últimas fotografias síntese escolhidas. [FIG. 4]

O conjunto das 20 fotografias é o que guiará, na ordem, a sequência das páginas. A fotografia da primeira escolha será sempre apresentada logo após uma página, com cortes especiais, que anunciarão a imagem 
Figura 4

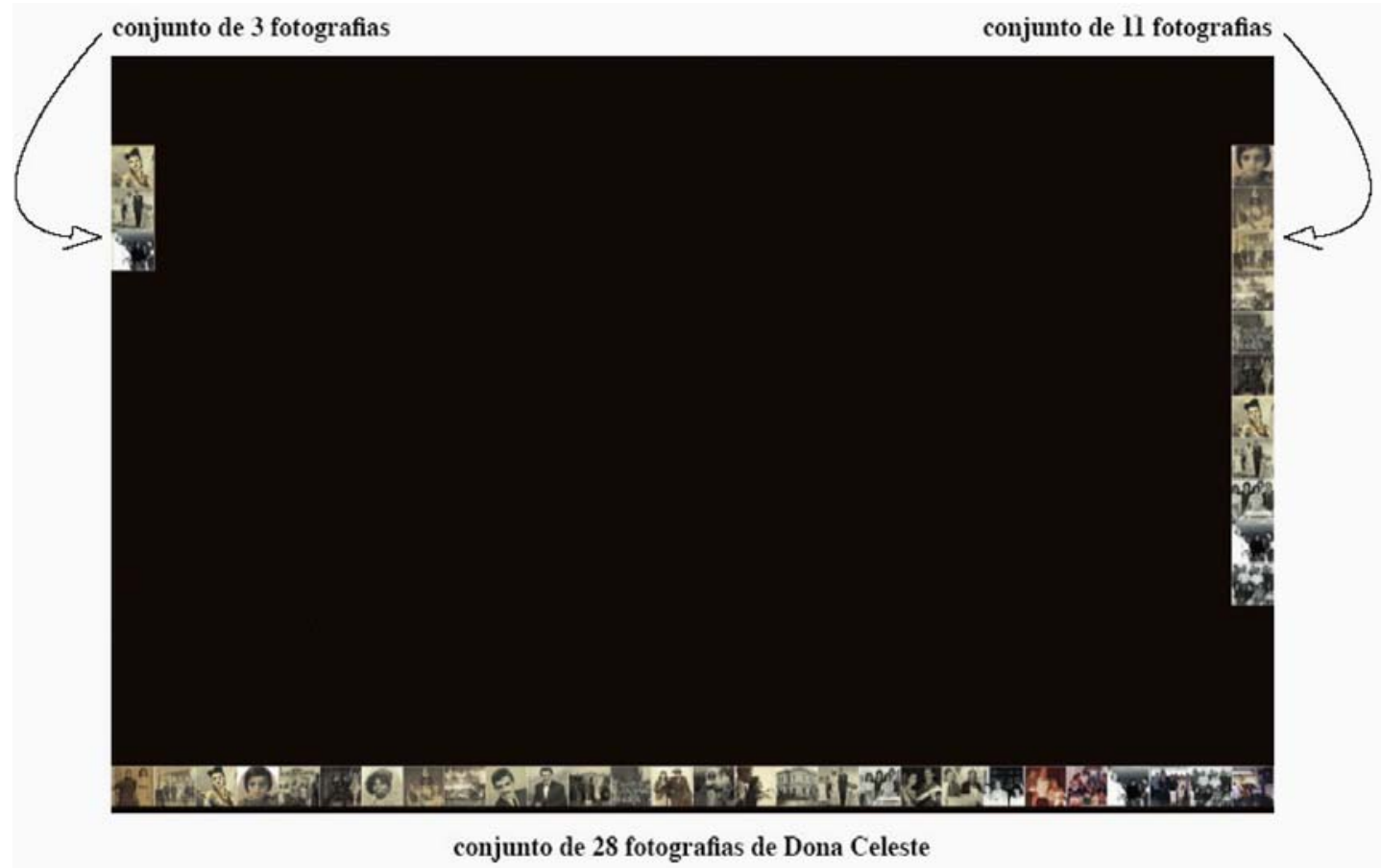

que virá ao lado de uma frase curta, um teaser, do texto que também seguirá. Esta janela que dará a fotografia um recorte diferenciado será uma maneira de trazer o leitor para um ponto de destaque da imagem (sugerida ou não pelo informante). Se pensarmos, de maneira análoga ao cinema, poderíamos interpretar esse recurso como aquele das câmeras que se aproximam, num close, do personagem para depois apresentá-lo no contexto de um cenário. Este recurso visual gráfico se enquadra, portanto, como mais uma proposta estética destas Fotobiografias. [FIGs. 5 e 6$]$

No caso desta mesma fotografia ter sido selecionada por ocasião da segunda escolha de 10 fotografias, esta página dará a pista por meio de uma fenda (faca gráfica) para indicar que na página debaixo haverá outra referência àquela imagem. A página seguinte trará, então, o texto relatado pelo informante, naquela ocasião, impresso em acetato (transparência). O texto transcrito na transparência é um convite a interagir com a Fotobiografia. Em contato com o fundo preto, as palavras escritas estarão apagadas, mas poderão ser descobertas pelo leitor com o movimento de um marcador (apenso) presente sob a transparência. [FIG. 7] 


\section{Figura 5}

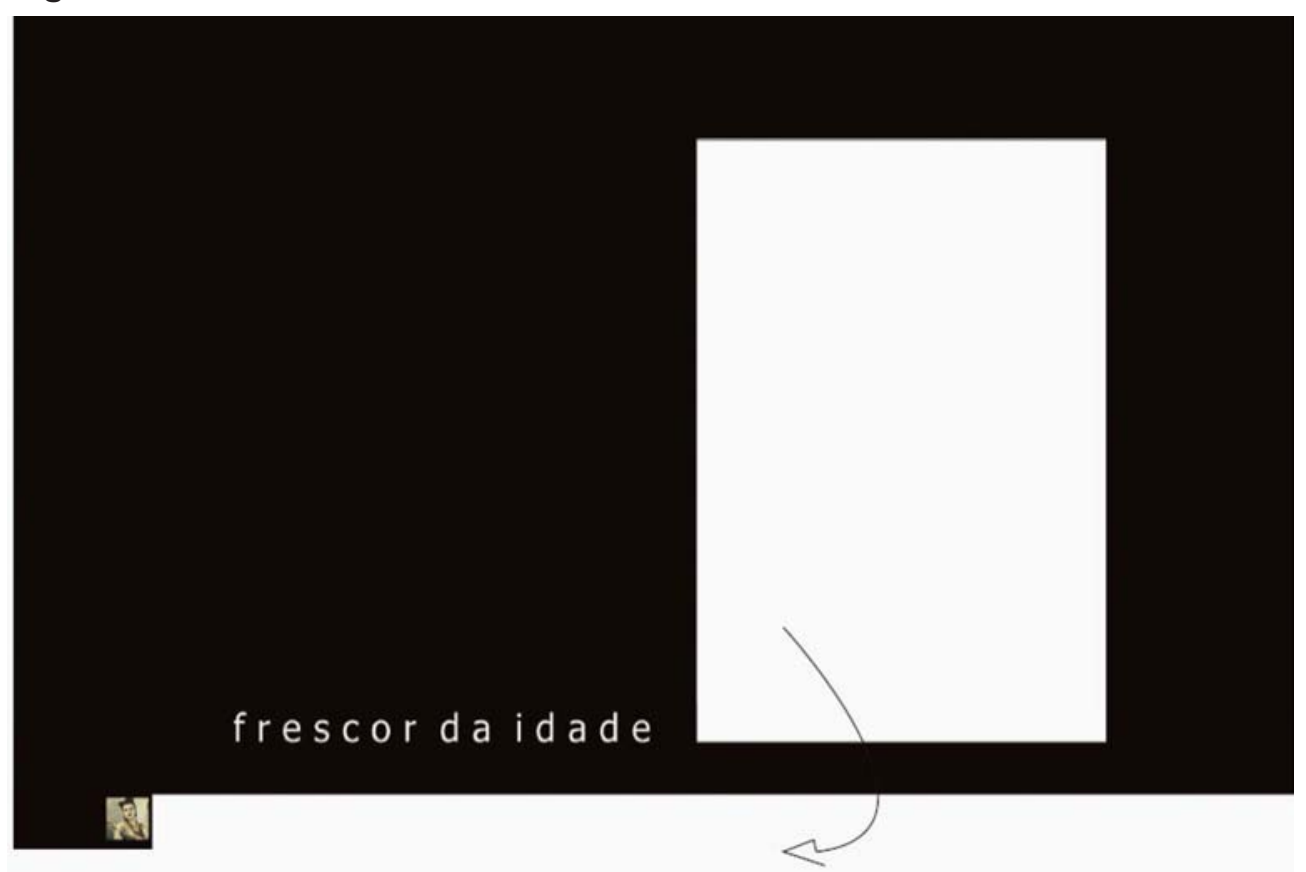

Prancha com demarcação do corte da faca gráfica.

Figura 6

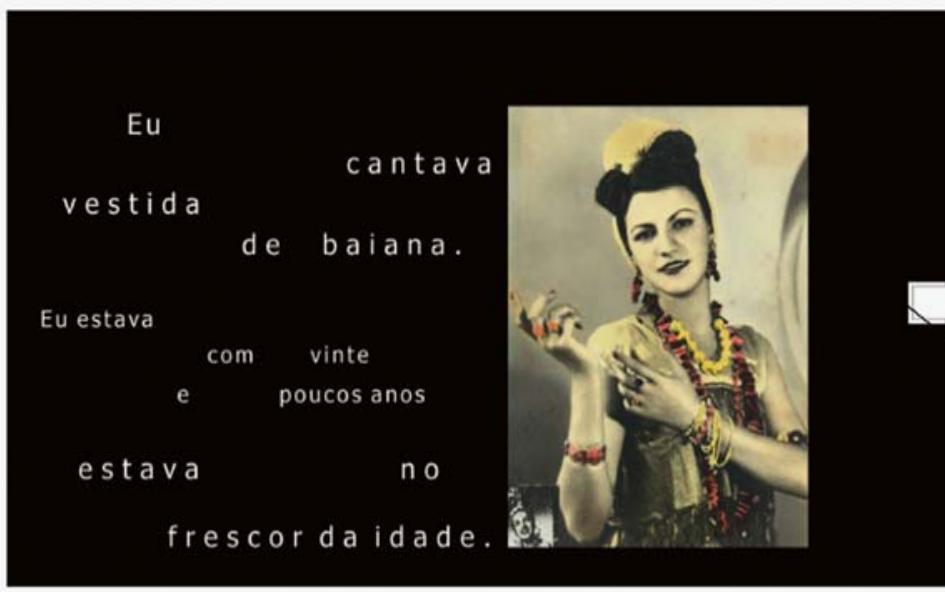

No caso desta mesma fotografia ter sido selecionada por ocasião da segunda escolha de 10 fotografias, esta página dará a pista por meio de uma fenda (faca gráfica), para indicar que na página debaixo haverá outra referência àquela imagem. A página seguinte trará, então, o texto relatado pelo informante, naquela ocasião, impresso em acetato (transparência). 
Figura 7

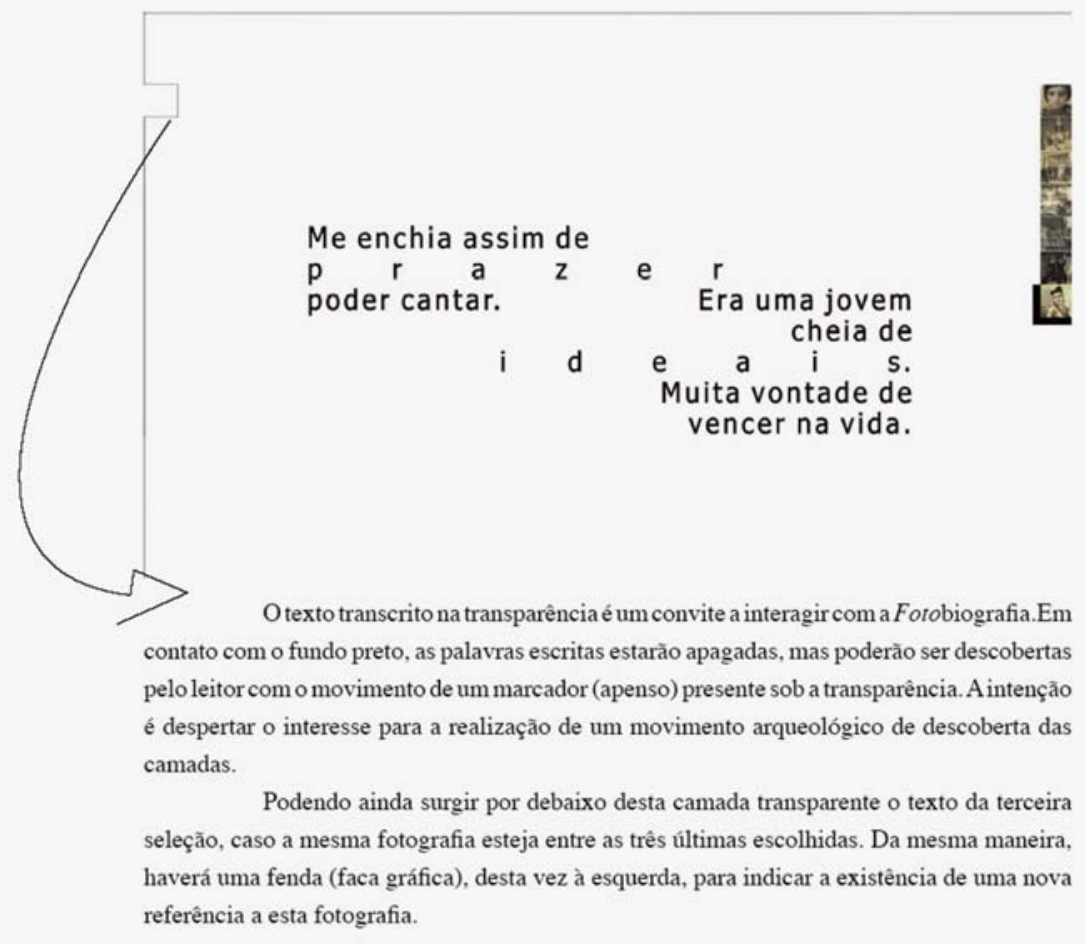

A intenção é despertar o interesse para a realização de um movimento arqueológico de descoberta das camadas. Podendo ainda surgir por debaixo desta camada transparente o texto da terceira seleção, caso a mesma fotografia esteja entre as três últimas escolhidas. Da mesma maneira, haverá uma fenda (faca gráfica), desta vez à esquerda, para indicar a existência de uma nova referência a esta fotografia. [FIG. 8]

A página que fará referência ao texto da terceira escolha virá sempre com um fundo preto e o texto impresso em branco. Desta maneira, toda vez que a escolha de uma mesma fotografia se repetir dentro dos três momentos da pesquisa, o leitor encontrará essas camadas sobrepostas de textos numa espécie de fusão. Esses textos, transcritos das entrevistas, poderão, assim, guardar a originalidade da forma como esses informantes se referiram a mesma fotografia em diferentes momentos acontecidos com intervalos de tempo. O leitor poderá constatar em que medida os textos se duplicam, se complementaram, ganharam nova ordenação ou se diferenciaram da primeira para a segunda e terceira escolhas, observan- 


\section{Figura 8}

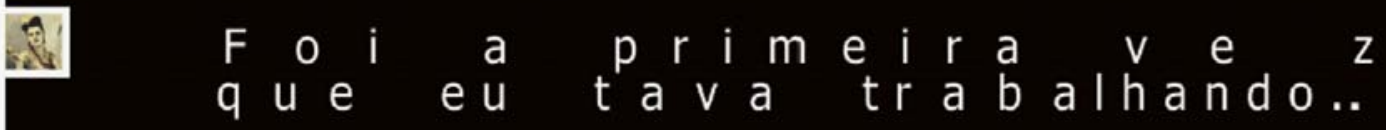
d e

A página que fará referência ao texto da terceira escolha virá sempre com um fundo preto e o texto impresso em branco.

do desta forma como se deu, portanto, o "trabalho da memória" do informante.

Desta maneira caberia dizer que cada camada é ao mesmo tempo resultante da ausência, do esquecimento, do desaparecimento por nós solicitado, de certas fotografias e da revalorização de novas memórias daquelas que permaneceram e que se enriqueceram de outros comentários. Não poderíamos descobrir necessariamente o que poderia significar em termos de valor, determinadas presenças imagéticas (pessoas, lugares, acontecimentos), se não tivéssemos as dimensões das outras fotografias que foram deixadas de lado para, portanto, reforçar a presença das que permaneceram.

Cada camada poderá ser lida separadamente como se fosse "uma leitura de um fragmento de uma história de vida", parte de um palimpsesto 
reencontrado ou, melhor dizendo, revivido na interioridade de uma pessoa. Palimpsesto, outrora e de certo modo apagado, mas nunca excluído. O que, deste modo, será o mais importante para o leitor - se dará, nesta possibilidade de leitura conjunta para alcançar a composição de uma Fotobiografia, nos moldes metodológicos desta pesquisa.

Notadamente encontramos outros territórios extremamente densos que exigirão mergulhos profundos para futuras pesquisas acadêmicas. Explorando o território descobre-se que toda imagem é, portanto, uma memória de memória(s). Memória de um tempo remoto que se distancia de suas origens, mas não está impedida de sobreviver no passado, no presente e no futuro, e participar com a imagem de uma montagem - nãohistórica - de tempo (para nos referirmos a Didi-Huberman, um dos autores que mais trouxe contribuições para esta pesquisa). A imagem, para a existência humana, poderá “continuar sendo...”; não se apagará, mas não será mais a mesma para a memória do seu passado e para as histórias da vida. Se tocada, por outro lado, como garante o mesmo autor, arde novamente. A imagem arde de vida, de memória e de futuro. Reavivadas guardam em parte lembranças, até de outras imagens, e de outras memórias. Não são, simplesmente, um corte no tempo e no espaço, como costumamos sempre dizer. As imagens passam... como fluxos... como pensamentos... como explosões de significações. As imagens fazem pensar e são "formas que pensam". No labirinto - da imagem e da memória - entramos, então, com o propósito de ter apresentado uma metodologia estética (antropológica) para cinco histórias de vida. E de dentro dos quadros deste labirinto garantimos estarmos ainda no começo de um desvendamento mais expressivo de singulares histórias de vida, não enclausuradas somente de palavras, mas embrenhadas na prioridade heurística do pensamento das imagens, signos, figuras, silêncios, contextos e também palavras.

\section{REFEREANCIAS BIBLIOGRÁFICAS}

BARTEHS, Roland. La Chambre Claire. Note Sur la Photographie. Paris: Cahiers du Cinéma-Gallimard- Seuil, 1980. [versão portuguesa: $A$ Câmara Clara. Nota Sobre a Fotografia. Rio de Janeiro: Editora Nova Fronteira,

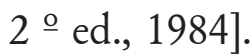


. "O terceiro sentido", In: O Óbvio e o Obtuso: Ensaios

Críticos III. Rio de Janeiro: Tempo Brasileiro, 1976. [original francês: 1970].

BRUNO, Fabiana. "Retratos da velhice: um duplo percurso metodológico e cognitivo". 2003. 309p. Dissertação (Mestrado em Multimeios) - Instituto de Artes, Universidade Estadual de Campinas, Campinas, 2003. 